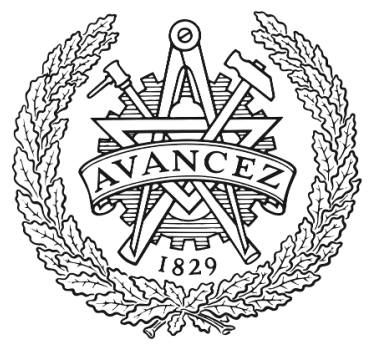

CHALMERS

UNIVERSITY OF TECHNOLOGY

\title{
Screening of how the organisation of life cycle nodes influences environmental impacts: A methodology
}

Downloaded from: https://research.chalmers.se, 2023-04-26 10:05 UTC

Citation for the original published paper (version of record):

Lindkvist, M. (2018). Screening of how the organisation of life cycle nodes influences environmental impacts: A

methodology. Journal of Cleaner Production, 204: 461-470.

http://dx.doi.org/10.1016/j.jclepro.2018.09.044

N.B. When citing this work, cite the original published paper. 


\section{Accepted manuscript}

for the article published as:

Lindkvist, Mathias (2018). Screening of how the organisation of life cycle nodes influences environmental impacts: A methodology. Journal of Cleaner Production 204: 461-470.

The published article can be accessed at https://doi.org/10.1016/j.jclepro.2018.09.044. 


\section{Screening of how the organisation of life}

\section{cycle nodes influences environmental}

\section{impacts: a methodology ${ }^{1}$}

Lindkvist, Mathias $^{\mathrm{a}}$

${ }^{a}$ Division of Environmental System Analysis, Department of Technology Management and

Economics, Chalmers University of Technology, SE-412 96 Gothenburg, Sweden

E-mail: mathias.lindkvist@chalmers.se

Telephone: $+46(0) 739728221$

Fax: not applicable

(C) 2018. This manuscript version is made available under the CC-BY-NC-ND 4.0 license

$\underline{\text { http://creativecommons.org/licenses/by-nc-nd/4.0/. }}$

${ }^{1}$ Abbreviations in the manuscript:

LCM = life cycle management

$\mathrm{LCNO}=$ life cycle nodal organisation

SMIP = socio-material interaction point

SSCM = sustainable supply chain management 


\section{Declaration of interest}

Declarations of interest: none.

\section{Abstract}

Environmentally effective governance requires avoiding sub-optimisation of product life cycles, and effective governance depends on addressing the nets of humans that organise these activities. This article combines these insights into a common approach. A test is performed of a quicker screening version of an existing approach to study how environmental performance depends on the organisation of the product life cycle nodes where environmentally important material flows meet. The test is conducted on five services and products: bowling, bread, coach services, concrete, and road management. Twenty-five different environmentally relevant practices are identified. The findings include: a case of maintenance routines not being reorganised until after a period of environmentally ineffective operation, a case of changing the supply methods due to difficulties in monitoring price fluctuations, and a case of contractors being unwilling to disclose environmentally-relevant information to their successors. The findings highlight that a screening approach can identify non-intuitive environmentally relevant organisational practices at life cycle nodes. Such findings can inform researchers about environmentally relevant aspects to consider, and they can inform managers and policymakers about strategic opportunities for and limitations on environmentally effective governance.

\section{Keywords}

organizing, life cycle assessment, socio-material, methodology, screening, node 


\section{Introduction}

The human activities that are considered to cause severe environmental problems do not exhibit signs of becoming more sustainable (cf., e.g., Janssens-Maenhout et al., 2017). Therefore, increased environmental effectiveness of the governance performed by businesses, authorities, and other actors is warranted. Two approaches that have been identified as important for facilitating environmentally effective governance are life cycle assessment (LCA) (e.g., Hauschild et al., 2018) and organisation studies (e.g., Kallio and Nordberg, 2006). An LCA is based on avoiding sub-optimisation of substantial environmental impacts from a product life cycle, which covers the technical processes in the production, use, and waste management of the product (Curran, 2012). Organisation studies have shown that many different interactions between humans, within a company or other formal organisation, and between organisations and other actors, determine the performance of an actor (Hatch and Cunliffe, 2006).

The established approaches that come closest to combining LCA with organisation studies are life cycle management (LCM) and sustainable supply chain management (SSCM). LCM takes a business perspective on life cycle environmental performance (Sonnemann and Margni, 2015). LCM research, however, lacks "descriptions or analyses of actual cases or of the difficulties involved in organizing LCM in practice" (Nilsson-Lindén et al., 2018: 7). SSCM addresses sustainability related to "the planning and control of materials, information flows, and the logistics activities internally within a company and also externally between companies" (Ahi and Searcy, 2013: 330). More than two organisations along a life cycle are, however, seldom considered (Carter and Liane Easton, 2011).

The limited focus on actual practices in LCM and the limited coverage of the whole product life cycle in SSCM have been addressed by research on populating LCA (Baumann, 2012). These studies have shown, among other things: that a caring approach to energy and 
water supply in residential buildings can be environmentally advantageous (Brunklaus, 2009a); and how the performance of a product responsibility policy was affected by the 'free riders' of a recycling system and a misunderstanding between key actors (Lindkvist and Baumann, 2017). These studies use a socio-material approach, which treats material objects and human actions as inseparable, in order to systematically combine an LCA-based study with a descriptive action net study (Czarniawska, 2008) of the net of human actions that can be traced from the product life cycle. Action nets follow links of human actions, rather than consider only one formal organisation or other formal actor as a unitary piece, and can, therefore, account for actors that are not isolated and who have changing roles (Czarniawska, 2008). In order to connect actions to product life cycles, populating LCA studies include socio-material interaction points (SMIPs), which are the points where human actions come the closest to product life cycle material flows, such as when a blue-collar worker adjusts a setting in a production plant or a consumer examines a product for sale (Lindkvist and Baumann, 2017).

The populating LCA approach can be developed further in terms of the extent of studying organisation, life cycles, and environmental performance. One variant of the approach has organisationally focussed on in-depth studies of one product life cycle node where environmentally important flows meet, such as a residential building. However, studies with this extent are time consuming (Brunklaus, 2008). The aim of this study is, therefore, to facilitate environmentally effective governance by screening how the organisation of a product life cycle node influences the life cycle environmental performance of the product. The hypothesis is that the proposed screening life cycle nodal organisation (screening LCNO) approach can be used efficiently to identify non-intuitive and environmentally relevant organisational practices that would not easily be found, or would require more resources to identify, using other approaches. Confirming this hypothesis would, for example, provide 
managers with a guide to finding and addressing organisational practices in order to gain competitive advantages by effectively reducing environmental impacts. On the other hand, a disproven hypothesis would point to a need for researchers to explore other ways of guiding environmental governance.

\section{Methodology and test case method}

The screening LCNO approach for studying product life cycle environmental performance and the organisation of life cycle nodes is presented in the following, and, in the next subsection, the method for testing this approach with five cases is described. The general delimitations build on the in-depth LCNO studies on housing management (e.g., Brunklaus, 2009a) and facilities management of supermarkets (Lundberg, 2008). In addition, the approach is informed by populating LCA research on the general approach (Baumann, 2004), terminology (Baumann, 2008), extent (Baumann, 2012), and testing (Lindkvist and Baumann, 2017). The test case method consists of an explorative study based on five services and products and a comparison of three relatively similar subcases within each of these main cases.

\subsection{The screening LCNO approach}

\subsubsection{Extent of the concepts}

The extent of a screening LCNO study is the environmental performance of the whole, or a large share of, a product life cycle as well as an action net that is traced from a product life cycle node. The combining of the two types of studies is illustrated in Fig. 1, and Fig. 2 shows flows and actions typically of concern in the approach.

Fig. 1. 
Fig. 2.

The components used in populating LCA studies are tailored in the screening LCNO approach. An LCA-based study consists of the findings from existing LCA studies or a screening LCA. SMIPs can typically indicate that the actual handling of flows may not correspond to decisions by top management (cf., Lindkvist and Baumann, 2017). The action net approach takes its point of departure in one business, or other actor, and takes into account related actors. Screening LCNO studies, thus, combine a broad life cycle perspective with a narrower organisational focus.

\subsubsection{Research techniques}

A range of techniques can be combined when performing a screening LCNO study. The techniques include: desk studies of reports, web pages, and research literature; and field studies through interviews and observation (cf., Silverman, 2006). The lenses of discourse analysis and conversation analysis are used to take into account that text and talk not only represent a reality but also have effects, and that a conversation is conditioned by earlier statements, respectively (cf., Silverman, 2006). The use of techniques in the approach facilitates customised and critical studies.

\subsubsection{Procedure}

The procedure in the approach consists of the following sequence except that the steps $2 \mathrm{a}-$ $2 \mathrm{c}$ are partly performed in parallel, and the procedure is similar to the one presented by Lindkvist and Baumann (2017): 


\section{Choosing the extent of the study.}

\section{Collecting data.}

a Product life cycle environmental performance: Identifying LCA results.

b SMIPs: Finding SMIPs, particularly at the flow nodes but also at other technical processes in the product life cycle.

c Action nets: Exploring action nets between the SMIPs.

3 Analysing: Analysing the environmental relevance of practices in the action nets.

The different techniques used in Step 2 of the procedure are chosen based on the situation at hand in a study, in line with the grounded theory approach (Glaser and Strauss, 2006).

\subsection{Test case method}

The screening LCNO approach was tested with the application of it to five cases of different services and products. The testing is described in the following.

\subsubsection{Choosing the extent of the study}

Five cases were used in order to make the testing broadly applicable. The services and products covered are bowling, bread, coach services, concrete, and road management. This allows for the study of: services and products; and heavy industry, staple products (bread), public procurement (road management), and leisure activities. The selection was guided by the considerable environmental impacts from the product life cycles of bowling (Ukidwe, 2005), bread (Andersson and Ohlsson, 1999), concrete (Vold and Rønning, 1995), and road management (Stripple, 2001). In addition, the identified organisational variation within each case, informed by an LCA on bread (Andersson and Ohlsson, 1999) and an environmental management study related to concrete (von Bahr et al., 2003), influenced the choice. The test 
case on coach services is derived from Lindkvist and Baumann (2015). Taken together, the cases have been selected in order to allow a diverse and relevant testing of the approach.

Comparisons between different subcases was made in order to identify actual differences between similar product life cycles and their organisation. The subcases were kept similar to each other, apart from organisational practices and environmental performance, thereby minimising the influence from other aspects, such as location and cultural context. This also made the study more practically feasible, because study objects could be chosen geographically close to the researcher. The units of comparison between the subcases are based on the standard procedure in LCA, where they are referred to as functional units.

The types of cases and subcases are outlined in Table 1, and Table 2 presents the specific nodes studied and the primary differences between them that were used as the rationales for their selection.

Table 1

Overview of the five cases used to test the approach

\begin{tabular}{|c|c|c|c|c|}
\hline $\begin{array}{l}\text { Cases - services } \\
\text { and products }\end{array}$ & Studied nodes & Location of nodes & $\begin{array}{l}\text { Organisational aspect that } \\
\text { warranted comparison }\end{array}$ & Unit of comparison \\
\hline Bowling & Bowling halls & $\begin{array}{l}\text { Gothenburg, } \\
\text { Sweden }\end{array}$ & $\begin{array}{l}\text { Several halls close to each } \\
\text { other }\end{array}$ & $\begin{array}{l}1 \text { occasion of } \\
\text { bowling for } 1 \text { person }\end{array}$ \\
\hline Bread & Bakeries & $\begin{array}{l}\text { Gothenburg and } \\
\text { Malmö, Sweden }\end{array}$ & $\begin{array}{l}\text { Different sizes of businesses } \\
\text { identified as influencing } \\
\text { environmental performance }\end{array}$ & $1 \mathrm{~kg}$ bread consumed \\
\hline Coach services & Coach routes & Gothenburg-Oslo & $\begin{array}{l}\text { Different operators on the } \\
\text { same route }\end{array}$ & $\begin{array}{l}1 \text { one-way trip on the } \\
\text { studied route for } 1 \\
\text { person }\end{array}$ \\
\hline Concrete & Cement plants & Southern Sweden & $\begin{array}{l}\text { Management practices } \\
\text { identified as influencing } \\
\text { environmental performance }\end{array}$ & $\begin{array}{l}1 \mathrm{~kg} \text { cement } \\
\text { produced }\end{array}$ \\
\hline $\begin{array}{l}\text { Road } \\
\text { management }\end{array}$ & $\begin{array}{l}\text { Districts for } \\
\text { operation and } \\
\text { routine } \\
\text { maintenance of } \\
\text { roads }\end{array}$ & $\begin{array}{l}\text { Gothenburg } \\
\text { metropolitan area }\end{array}$ & $\begin{array}{l}\text { Different administration } \\
\text { areas with similar types of } \\
\text { roads }\end{array}$ & $\begin{array}{l}\text { The operation and } \\
\text { routine maintenance } \\
\text { of } 1 \mathrm{~km} \text { road }\end{array}$ \\
\hline
\end{tabular}


Table 2

Test case nodes

\begin{tabular}{ll}
\hline Organisations and locations & $\begin{array}{l}\text { Overarching characteristics that distinguish the subcases } \\
\text { from one another }\end{array}$ \\
\hline Bowling - bowling halls & Many services provided \\
A: Star & A moderate number of services provided \\
B: Majorna bowling & Few services provided \\
C: Valhalla Bowling & \\
Bread - bakeries & Large production size \\
A: Pågen in Gothenburg & Moderate production size \\
B: Dahls & Small to moderate production size \\
C: Ambrosia & \\
Coach services - coach routes & Premium services \\
A: Bus4You & Mid-range services \\
B: GoByBus & Budget to mid-range services \\
C: Swebus Express & \\
Concrete - cement plants & Large production size \\
A: Slite & Moderate production size \\
B: Skövde & Small to moderate production size \\
C: Degerhamn & \\
Road management - districts for operation & \\
and routine maintenance of roads & \\
A: Ale, Kungälv, Stenungsund, and Tjörn & Moderate to long road length \\
B: Kungsbacka & Moderate road length \\
C: Gothenburg & Short to moderate road length \\
\hline
\end{tabular}

\subsubsection{Collecting data}

The following procedure was used in each subcase (based on Step 2 in the procedure presented in Subsection 2.1.3) to collect data to test the screening LCNO approach:

1 Product life cycle environmental performance, initially: desk studies

2 SMIPs, initially: desk studies

3 Action nets, initially: desk studies

4 All components: field studies, primarily for identifying action nets

5 All components, complement: desk studies, particularly for studying product life cycle environmental performance

The use of sources varied in some primary ways between cases and subcases: 
- Desk studies: For example, more in-depth and rigid environmental information was available for cement plants (cf., Cementa, n.d.) than for other nodes (cf., e.g., Stripple, 2001) due to the heavy pressure on the former ones to improve their environmental performance.

- Field studies, interviews: They were based on finding a person who had an overview of the hands-on steering of material flows.

- Field studies, observation: This was performed as a customer where interviews were less feasible.

The desk studies were performed primarily in 2010-2013, and the field studies were carried out in 2009-2010. An overview of the data sources is presented in Table 3. 
Table 3

Primary test case data sources. The designations A-C refer to the organisations and locations outlined in Table 2. 


Bowling - bowling halls
Desk studies
Web pages
Research literature

Field studies

Observation

Bread - bakeries

Desk studies

Web pages

Research literature

Field studies

$\begin{gathered}\text { Interviews and } \\ \text { observations combined }\end{gathered} \quad \mathrm{A}, \mathrm{B}$, and C

\section{Coach services - coach routes}

Desk studies

Web pages A, B, and C

Field studies

Observation $\quad \mathrm{A}, \mathrm{B}$, and $\mathrm{C}$

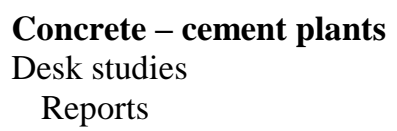

Research literature Product life cycle environmental performance of concrete in the Nordic countries

Field studies

Interview and observation B combined

\section{Road management - districts for operation and routine maintenance of roads}

Desk studies

Web pages

Research literature

Field studies Interviews

\section{$\mathrm{A}$ and $\mathrm{B}$}

Bowling hall suppliers globally

Product life cycle environmental performance of bowling in the USA Product life cycle environmental performance of other leisure activities in Europe

$$
\mathrm{A}, \mathrm{B} \text {, and } \mathrm{C}
$$

\section{A and B}

Product life cycle environmental performance of bread globally
Road management in Sweden Road management in Sweden

Product life cycle environmental performance of road management in Sweden
A, B, and C

About the services provided About bowling hall equipment One LCA

LCAs

Studied as a customer

About the product life cycles Bread LCAs

Interviews with a production manager (A), a production supervisor (B), and a CEO and master baker $(\mathrm{C})$, and observation of a small (A), large (B), and full (C) share of the production facility

About the organisation and environmental practices

Studied as a travelling customer, and at coach stands and ticket offices at the Gothenburg coach station

Environmental reports Proceedings of a production permit renewal One LCA

Interview with an environmental coordinator and observation of the primary technical processes
Interviews with the two project leaders for operation and routine maintenance of the districts 


\subsubsection{Analysing}

The analysis focussed on creating and comparing descriptions of environmentally relevant practices. The findings were structured based on the SMIPs involved. In addition, the relations between the relevant practices identified were considered. These approaches were used in order to use LCA as a basis and to show potential differences not captured by LCA.

\section{Results}

Test case findings on how the organisation of life cycle nodes can influence the environmental performance of product flows are presented here. Product life cycle environmental performance, potentially environmentally relevant practices, and relevant but less obviously connected or less obvious SMIPs are outlined. Illustrations of the product life cycles are provided in Fig. 3 and overviews of the practices are presented in Table 4.

Fig. 3. 
Table 4

Practices that influence the product life cycle environmental performance of the five test cases

\begin{tabular}{|c|c|}
\hline Groups of practices & Specific practices and their relations to environmental performance \\
\hline \multicolumn{2}{|l|}{ Bowling - bowling halls } \\
\hline \multirow[t]{4}{*}{ Types of services } & Disco bowling - lane wear and bowling time \\
\hline & Additional games - apparent impacts and bowling time \\
\hline & Restaurants, bars, and kiosks - apparent impacts and bowling time \\
\hline & Lunch provision - fill rates \\
\hline Maintenance & Level - apparent impacts and repair needs \\
\hline Ceasing of business & Utilisation rate, and types of services and maintenance \\
\hline \multicolumn{2}{|l|}{ Bread - bakeries } \\
\hline \multirow[t]{2}{*}{ Supply } & Distance increase \\
\hline & Optimisation \\
\hline \multirow[t]{3}{*}{ Production } & Product types - loaf thickness \\
\hline & Sealed production - durability and consumer storage \\
\hline & Packaging - apparent impacts, durability, and consumer storage \\
\hline Distribution & Distance \\
\hline Retail & Discarding \\
\hline \multicolumn{2}{|l|}{$\begin{array}{l}\text { Coach services - coach } \\
\text { routes }\end{array}$} \\
\hline \multirow[t]{2}{*}{ Vehicle sourcing } & Fleet age \\
\hline & Seats per row \\
\hline Garage related & Location \\
\hline \multirow[t]{3}{*}{ Passenger transport } & Eco-driving use and discussion \\
\hline & Smooth driving \\
\hline & Scheduling related to rush hours \\
\hline \multicolumn{2}{|l|}{ Concrete - cement plants } \\
\hline \multirow{2}{*}{$\begin{array}{l}\text { Emission reduction } \\
\text { techniques }\end{array}$} & Production permit renewal processes \\
\hline & Production permit renewal infrequency \\
\hline Maintenance & Malfunctioning routines \\
\hline \multicolumn{2}{|c|}{$\begin{array}{l}\text { Road management - } \\
\text { districts for operation } \\
\text { and routine maintenance } \\
\text { of roads }\end{array}$} \\
\hline Transports between districts & Centralisation by contractors - increasing transports \\
\hline \multirow[t]{2}{*}{ Operation and maintenance } & Change of contractor - withholding of expertise \\
\hline & $\begin{array}{l}\text { Fragmentation of procuring agency - difficult to handle the overarching } \\
\text { environmental issues }\end{array}$ \\
\hline
\end{tabular}

\subsection{Bowling}

The following findings from the bowling test case are based on studies of the bowling halls Star (A), Majorna Bowling (B), and Valhalla Bowling (C), in Gothenburg, Sweden.

\subsubsection{Environmental performance overview}

The identified primary material flows of the bowling product life cycles (shown in Fig. 3) were found to result in environmental impacts of notable overall magnitude compared to other products and services (Ukidwe 2005). Generic environmental impacts were identified for 
building construction materials, energy supply, bowling lane equipment and maintenance, decoration, information technology systems, food and beverage provision, and other games provided. In particular some aspects are considered important because the literature shows considerable impacts from them in other leisure activities. It has been reported for theatre and opera shows that building related services and energy provision can cause up to around $30 \%$ of the global warming potential and that restaurants caused up to around $20 \%$ of the eutrophication potential (cf., Tengström and Izurieta, 2010). Both general and particularly relevant impact sources are, thus, found.

\subsubsection{Environmentally relevant practices}

Six practices of product life cycle environmental relevance were identified. The practises relate to SMIPs at the bowling halls regarding services provided, maintenance, and ceasing of business (see also Table 4).

The relevant services provided are disco bowling, additional games, restaurants, bars and kiosks, and lunch provision. Disco bowling includes background music and fluorescent lighting. These can influence environmental impacts through a greater need for maintenance due to lane wear, and by providing entertainment that leads to additional satisfaction, which results in less time per occasion and, thus, less background environmental impact from, for example, building related services per bowling occasion. The share of the opening hours used for disco bowling varied considerably. This bowling service was provided during all opening hours by A, was provided during some opening hours by B, and was not provided by C. A number of non-obvious SMIPs were identified. These include customers bowling, enjoying music, and arriving to and departing from the halls. Additional games could influence environmental performance through the materials and energy required for producing the services, and, similar to disco bowling, by reducing the overall bowling time. These services were provided by A. Non-obvious SMIPs, therefore, could include customers enjoying 
additional games. The services of restaurants, bars, and kiosks could result in environmental impacts from the consumption of food and drink that otherwise would not occur, and from either increasing or reducing overall bowling time. Restaurants and bars were found at $\mathrm{A}$ and B, whereas only a kiosk service was found at C. Lunch combined with bowling could result in better fill rates and in associated effects on materials and energy requirements. Of the three halls, only A provided lunch bowling. Consequently, non-obvious connections were identified between SMIPs at the use of the bowling lanes and the adjusting of the indoor temperature, among other things.

Maintenance can increase environmental impacts through the production of cleaners and conditioners (cf., Brunswick, 2012), and it can decrease impacts by preventing more severe damage that results in the need for lane repair. The maintenance level was found to be of relevance in the test case because it was high at $\mathrm{A}$, moderate at $\mathrm{B}$, and low at $\mathrm{C}$.

Ceasing of business was found to be a relevant aspect. Bowling halls require building shells and specific indoor dimensions and layout to suit the lanes. The building construction requires material and energy inputs, and the layout may not be suitable for other activities. If the premises are unused, the average impact from construction in relation to bowling occasions increases. The $\mathrm{C}$ hall closed their operation during the study. The result was that the premises were left unused for at least a few years. The closing down was likely connected to too few customers due to the hall's smaller range of services and lower level of maintenance. Through these findings, non-obvious connections were identified between SMIPs, for example, building construction and installing equipment for additional services.

The bowling case resulted in identifying environmentally relevant practices that were all linked to one another by business ceasing or not. 


\subsection{Bread}

The following findings from the bread test case are based on studies of the Swedish bakeries Pågen (A) and Dahls (B) in Gothenburg and the bakery Ambrosia (C) in Malmö, Sweden.

\subsubsection{Environmental performance overview}

Product life cycle environmental impacts were identified using LCA results for Swedish bread produced at different scales of business (Andersson and Ohlsson, 1999) and for different types of bread and distribution distance (SIK, 2009). The identified primary material flows are illustrated in Fig. 3. Environmental impacts from an LCA perspective were connected to processes throughout the product life cycles. The processes upstream of consumption were found to be important, by contributing to up to around at least $90 \%$ for the impact categories energy use, global warming, acidification, eutrophication, and tropospheric ozone. The reported impacts depend considerably on certain technical processes closely related to each bakery, and the findings about product life cycle energy use illustrate this. This energy use varied by up to $20 \%$ depending on supply and distribution ranges, was caused by up to $40 \%$ by the baking, varied by up to $20 \%$ depending on the packaging, and was caused by up to $20 \%$ by consumer storage. Consequently, several different processes and chain effects are relevant.

\subsubsection{Environmentally relevant practices}

Seven practices of product life cycle environmental relevance were identified. They relate to SMIPs at: the supply to, production in, and distribution from the bakeries; and retail (see also Table 4).

The supply related practices are distance and optimisation. The supply distance was found to have increased at $\mathrm{C}$, while no supply distance changes were identified at $\mathrm{A}$ and $\mathrm{B}$. The 
apparent increase was due to a switch from local suppliers to a nationwide organisation owned by several bakeries. The small bakery could not monitor the increasing price fluctuations for certain necessary patisserie ingredients, and, consequently, all of the bakery's purchasing had been taken over by the nationwide organisation. Non-obvious connections were, thus, identified between SMIPs at the suppliers and the $\mathrm{C}$ bakery. Supply optimisation is based on the product amount provided per vehicle and how full its cargo load is. The optimisation was highest for A due to large volumes, and, consequently, required less vehicle fuel consumption per distance and amount of supplies. The identified supply aspects differ both between actors and over time.

Relevant production practices were identified regarding product type, sealed production, and packaging. The product types differed because only bakery A focussed on producing thin leavened bread. This had reduced the baking from around eight to three minutes and is considered to reduce the environmental impact from oven heating. Bakeries B and C primarily produced loaves of bread. Sealed production was only found at A, and this method was used to avoid contamination in order to ensure long and predictable bread durability. This is considered to reduce the consumer discarding of mouldy bread, which would reduce the environmental impacts because of less additional bread production. Sealed production can, in addition, decrease the freezing of short-durability bread, and increase the refrigeration of long-durability bread. Production sealing is made possible by a large bakery size. Nonobvious connections were, therefore, found between SMIPs at supplying sealing equipment and storing bread. Packaging for each sales item was only applied at A where it was used due to long-distance distribution. The environmental impacts depend on the difference between the product life cycle processes of this packaging and of potential use of packaging at a later stage (e.g., by customers) of bread not packaged at the bakery, and these impacts also depend 
on the effects of increased durability. Production practices can, thus, influence other product life cycle processes.

The bakery distribution range varied considerably. The distance was: up to $1200 \mathrm{~km}$ for A, $50 \mathrm{~km}$ for $\mathrm{B}$, and $10 \mathrm{~km}$ bakery $\mathrm{C}$. A large scale of business generally requires a larger distribution area, and is, therefore, environmentally relevant.

Discarding at retailers differed. Such discarding leads to an increase in environmental impacts via an additional need for bread production. Bakery A employed a planned 3\% takeback rate in order to provide its customers with a broad assortment. Returned products were used as animal fodder. No retailer discarding was identified at bakery B. Bakery C, in contrast, had encountered high levels of discarding. One issue was that the chief executive officer planned the production but had limited time to monitor the growing number of retailers. In addition, customer demands varied and included a preference for fresh and nonpackaged bread of all produced types to be available throughout the opening hours. Nonobvious connections were, consequently, identified between SMIPs, for example, selecting the amount of baking ingredients to use and customers considering to purchase bread.

The bread case resulted in identifying environmentally relevant practices that were more or less linked to one another through the scale of production.

\subsection{Coach services}

The following findings from the coach services test case are based on studies of three operators on the approximately $300 \mathrm{~km}$ long route Gothenburg-Oslo: Bus4You (A), GoByBus (B), and Swebus Express (C).

\subsubsection{Environmental performance overview}

Product life cycle environmental performance was identified based on observations as a travelling customer and at the coach station in Gothenburg. The identified primary material 
flows are illustrated in Fig. 3. Generic environmental impacts were found, such as global warming and acidification potentials, from product life cycles of coach fuel and the vehicles.

\subsubsection{Environmentally relevant practices}

Six practices of product life cycle environmental relevance were identified. The practices relate to SMIPs at the vehicle sourcing, at garages, and concerning passenger transports (see also Table 4).

Fleet age and seats per row were sourcing relevant. Fleet age influences environmental impacts from driving and vehicle production. Heavy-duty vehicle emissions are governed by European Union legislation. However, newer standards do not guarantee less impact. A comparison of a Swedish study on busses (Jerksjö and Hallquist, 2016) and the legislation (Dieselnet, 2016) shows that particle emissions decreased considerably between the 2000 Euro III and 2008 Euro V standards, whereas nitrogen oxide emissions doubled. The fleet was brand new for A, new but not brand new for B, and of varied age for C. Due to the considerable weight of the vehicle compared to that of the passengers, the number of seats per row influences emissions per person and trip. The number of seats per row was $2+1$ for operator A and $2+2$ for the other two operators. Both the vehicle construction itself and the influence from its design are, thus, relevant.

Garages provided the locations for parking, filling up on fuel, and maintaining the coaches for the three operators. Trips to and from the garages add to fuel use and associated environmental loads. The garage was co-located at the Gothenburg coach terminus for operator C and lay in the city of Borås, Sweden, around $70 \mathrm{~km}$ from the Gothenburg terminus, for the other operators.

Passenger transport is related to eco-driving, smooth driving, and scheduling.

Conservatively, eco-driving reduces fuel consumption by 10\% (Barkenbus, 2010). Drivers for $\mathrm{C}$ received eco-driving training and those drivers often shared experience, aiming to drive 
more eco-friendly. No information on potential eco-driving practices at the other operators was found. Non-obvious connections were, thereby, found between SMIPs on different ecodriving occasions. Smooth driving has been found to decrease fuel consumption by around $20 \%$ to $30 \%$ (Sivak and Schoettle, 2012). Less smooth driving was observed occasionally for operator $\mathrm{C}$ but not for the other two operators, and was, therefore, a relevant aspect. The coach services offered by operator $\mathrm{C}$ were scheduled with the goal of avoiding rush hour traffic for emission reasons. Operator B had adopted almost the same scheduling as operator C, and no information on scheduling was available for operator A. Scheduling and driving style can, consequently, influence the environmentally performance.

The coach services case resulted in identifying environmentally relevant practices that were only linked to one another by the relation between fleet age and seating. These were connected by operator A providing a high comfort level.

\subsection{Concrete}

The following findings from the test case on concrete are based on studying the Swedish cement plants at Slite (A), Skövde (B), and Degerhamn (C).

\subsubsection{Environmental performance overview}

Product life cycles were identified by the means of an LCA study (Vold and Rønning, 1995) on concrete production from cement produced in plants in the Nordic countries and a guided tour. Fig. 3 illustrates the primary identified material flows.

Based on the LCA and environmental reports to authorities from the plants at Slite (Cementa, 2008c), Skövde (Cementa, 2008b), and Degerhamn (Cementa, 2008a), the majority of the potential environmental impacts from the concrete product life cycles stemmed from emissions at the process of clinker burning in the cement kiln at the cement plant and the supply of fossil fuel to this process. 


\subsubsection{Environmentally relevant practices}

Three practices of product life cycle environmental relevance were identified. The practices relate to SMIPs at the cement plants regarding nitrogen oxides emission reduction techniques and maintenance (see also Table 4).

Practices related to emission reduction techniques concern the processes and frequency of production permit renewal. Renewal of these permits is one of the major ways for environmental authorities to negotiate with cement plants. A long negotiation process to renew a permit for plant $\mathrm{C}$ led to emissions reaching a level around $40 \%$ lower than the level plant representatives initially claimed to be the lowest possible, and emission reached a lower level than requested by the authorities, according to the environmental report (Cementa, 2008a) and the routine court proceedings (Växjö Tingsrätt, 2007). However, several decades had passed since the previous permit had been renewed for plant $\mathrm{C}$, and renewal was sought only when a plant expected a production level higher than the current permit allowed. Both the rigour and infrequency of the renewals can be relevant.

Maintenance routines at plant B had been ineffective for a longer period before the study. Coordination of monitoring and maintenance action was introduced after a serious incident occurred as a result of poor maintenance. The routines were found to have been ineffective in 2007, and the annual carbon dioxide emission per tonne cement produced at the plant was $7 \%$ higher for that year than for 2006. This is in contrast to a decrease of 9-10\% during the same period at the other two plants (Cementa, n.d.). Consequently, non-obvious connections were identified between SMIPs at monitoring and maintenance.

The test case on concrete resulted in the identification of environmentally relevant practices where a connection was found between the two practices on emission reduction techniques. 


\subsection{Road management}

The following findings from the road management test case are based on studies of three districts for the operation and routine maintenance of roads in the Gothenburg metropolitan area, in Sweden: Ale, Kungälv, Stenungsund, and Tjörn (A), Kungsbacka (B), and Gothenburg (C).

\subsubsection{Environmental performance overview}

The identified activities in the operation and routine maintenance include road lighting, winter conditions management (such as the use of road salt and physical clearing of snow), mowing of grass, and clearing of verges (Stripple, 2001). The related primary material flows are illustrated in Fig. 3. The identified environmental impacts are related to electricity supply, fuel use, and materials for managing winter conditions (Stripple, 2001).

\subsubsection{Environmentally relevant practices}

Three practices of product life cycle environmental relevance were identified. The practices relate to SMIPs at the transports between districts, and operation and maintenance (see also Table 4).

Transports were affected because contractors in the Gothenburg metropolitan area had managed to win the tender for adjacent districts. The purpose was to centralise human and machinery resources, which would increase the transport needs, resulting in increased associated environmental impacts. The outsourcing of road management was initiated in the early 1990s, and the government agency that, prior to this time, had performed the road management was less pressured to centralise due to the absence of competition. The economic gain was coupled with increased environmental impacts.

Operation and maintenance were found to be relevant regarding renewed contracts and in the fragmentation of the procuring agency. The renewal of a contract with the same contractor 
led to lowered environmental impact (Faith-Ell et al., 2006). On the contrary, a new contractor was only little informed about practices during a hand-over due to competitive reasons, which resulted in environmentally inefficient operation. This was not an issue before the outsourcing was initiated in the early 1990s. Non-obvious connections were, therefore, found between SMIPs where the operation and routine maintenance are performed. The procuring organisation was found to increasingly govern contractors through a larger number of different channels, which caused fragmentation. This change was reported to lead to greater ineffectiveness and could reduce the opportunities for handling the typically overarching environmental issues. Environmental effectiveness and efficiency, thus, related to information transfer.

The road management test case resulted in the identification of environmentally relevant practices where the planning and contract renewal aspects were linked to each other through the presence or not of procurement.

\subsection{Synthesis of the five cases}

The results from the five cases show a large number of different environmentally relevant practices that relate to one another to varying degrees. SMIPs and actions of particular interest are related to the types of services provided, maintenance, and ceasing of business in the bowling case. From the coach services case, findings are produced on sourcing, garage location, and passenger transport. In addition, the relevance of the process of renewing a production permit was only encountered in the cement case, and the impact of unwillingness to forward expertise from one contractor to the succeeding one was specific to the road management case. Consequently, case-specific studies could provide advantages to general guidelines.

The situation is further complicated by the varying degree of connections between different relevant practices within each case. The scale of production was a link between 
distribution distance, packaging, and the other identified practices regarding bread. However, only fleet age and seats per row were interconnected among the six findings on coach services. Therefore, a careful combination of changes to practices may be necessary for substantial overall environmental improvement for some product life cycles.

\section{Discussion}

This section compares the results from testing the proposed approach to the related literature on greener products, SSCM, LCM, and in-depth LCNO studies.

\subsection{Life cycles and the environment}

A screening LCNO study is, despite being a screening, based on LCA that considers whole chains and different environmental impacts. This is illustrated in the test case results regarding effects of discarding practices on both other product life cycle steps and different environmental impacts in the bread case. The case on concrete shows the importance of the management of technical processes at the studied node. An LCA perspective is, thus, warranted.

Product life cycles and environmental performance are also considered in studies on greener products and SSCM. The studies include findings on reducing the contents of harmful substances in food products (Maroušek et al., 2017), success factors for sustainable product innovation (de Medeiros et al. 2014), and strategies for cooperation between actors along supply chains (Xie, 2016). The studies have produced in-depth analyses of specific features either on one environmental aspect or on the management factors involved in the sustainable product discourse. On the other hand, the environmental consideration of whole product life cycles and the estimation of different environmental impacts are not in focus. The test of the screening LCNO approach has not produced detailed knowledge, but it may complement greener product and SSCM studies through an explicit inclusion of LCA. 


\subsection{Specific descriptions and variation of practices}

Both specific characteristics of each practice and differences between the findings can be identified in Section 3. The change to a cooperatively owned supplier, in the bread case, and the competitive reasons for withholding information, in the road management case, exemplify specific characteristics. The focus on maintenance and permit renewal, in the case about concrete, and the coverage of types of services and seizing of business, in the bowling case, show variation between cases.

This focus on details could complement other approaches. LCA thoroughly covers product life cycles and different environmental impacts (Hauschild et al., 2018). However, LCA does not cover the human actions that change technical processes and determine their operation. Similarly, technical greener product studies highlight how the design of an environmentally promising product may look, but these studies do not go into the practical possibilities of implementing a product design and of attaining a desired product use (cf., e.g., Maroušek, 2014). In addition, LCM literature suggests using different existing environmental management and management tools, and it considers general aspects such as cooperation. The LCM focus provides familiarity to managers, but only provides little guidance on how to influence the actual human actions that cause environmental impacts. For example, Gemechu et al. (2015) have suggested identifying impacting life cycle stages, the availability of new technologies, and how competitors address impacts.

\subsection{Relations between practices}

Focussing on the nets of human actions and following a screening approach make it possible to identify relations between different environmentally relevant practices. For example, the bowling case highlights that lunch provision and disco bowling can give rise to environmental impacts more directly and by staying in business, and a range of practices that 
influence discarding waste bread are identified in the bread case. Some practices are found to reinforce each other environmentally and others tend to counteract each other in terms of sustainability.

Other approaches also aim to identify environmentally relevant management and organisation. SSCM focusses on drivers and barriers for implementation and mathematical analysis, which makes it possible to give concise advice, but which could be complemented with highlighting the potential organisational complexity of relevance (cf., e.g., Ansari and Kant, 2017). Similarly, more in-depth LCNO studies have tended to lead to identifying overarching logics as driving a number of different organisational practices that govern environmentally relevant practices (cf., Brunklaus, 2009a).

\subsection{Efficiency}

The test of the screening LCNO approach shows that it can be efficiently used for identifying 25 environmentally relevant practices for five types of product life cycles with three subcases each. In one in-depth LCNO studies of two organisations for one type of product life cycle, 18 full working days were needed for on-site data collection (Brunklaus, 2009a). The size of this data collection is considerably larger than of the five interviews and observation occasions and a few visits as customer in the test of the screening LCNO approach.

\section{Conclusion}

The test of the proposed approach led to the efficient identification of 25 non-intuitive environmentally relevant organisational practices that would not easily be found, or would require more resources to identify, using other approaches. Therefore, the hypothesis of the article has been confirmed. This has implications for different actors. Managers, policymakers, researchers, as well as persons in other organisational positions and citizens, 
could be made more aware of and comprehend the opportunities of, as well as the limitations to, influencing the many practices and nets of human actions that determine environmental impacts. Perhaps certain practices are too complex for each involved person to act on his or her own initiative, but it may be necessary to understand and communicate about such complexity before adopting overarching policies.

\section{Acknowledgements}

I would like to thank: the reviewers for feedback that was useful for improving the article; Rickard Arvidsson for two helpful reviews of the paper; and Henrikke Baumann and Birgit Brunklaus for valuable comments during the research and writing processes. Funding: This work was supported by the Swedish Research Council. The funding source was not involved in study design; in the collection, analysis and interpretation of data; in the writing of the report; or in the decision to submit the article for publication.

\section{References}

Ahi, P., Searcy, C., 2013. A comparative literature analysis of definitions for green and sustainable supply chain management. J. Clean. Prod. 52, 329-341. https://doi.org/10.1016/j.jclepro.2013.02.018

Andersson, K., Ohlsson, T., 1999. Life cycle assessment of bread produced on different scales. Int. J. Life Cycle Assess. 4, 25-40. https://doi.org/10.1007/BF02979392.

Ansari, Z.N, Kant, R., 2017. A state-of-art literature review reflecting 15 years of focus on sustainable supply chain management. J. Clean. Prod. 142, 2524-2543. https://doi.org/10.1016/j.jclepro.2016.11.023.

Barkenbus, J.N., 2010. Eco-driving: An overlooked climate change initiative. Energy Policy 38(2), 762-769. https://doi.org/10.1016/j.enpol.2009.10.021. 
Baumann, H., 2012. Using the life cycle approach for structuring organizational studies of product chains. 18th Greening of Industry Network Conference, 22-24 October, Linköping Congress Centre, Sweden.

Baumann, H., 2008. Simple material relations handled by complicated organisation by or "How many (organisations) does it take to change a lightbulb?" What is an Organization? Materiality, Agency and Discourse, 21-22 May, Université de Montréal, Québec.

Baumann, H., 2004. Environmental assessment of organising: Towards a framework for the study of organisational influence on environmental performance. Prog. Ind. Ecol. 1(1-3), 292-306. https://doi.org/10.1504/PIE.2004.004684.

Brunklaus, B., 2009a. Does organising matter? Tracing connections to environmental impacts in different housing estates. Prog. Ind. Ecol. Int. J. 6(2), 120-134. https://doi.org/10.1504/PIE.2009.029078.

Brunklaus, B., 2009b. Litteraturstudie Kring Miljöpåverkan av Immateriell Konsumtion, Dvs. LCA av Tjänstekonsumtion [Literature Study on Environmental Impacts from Immaterial Consumption - LCA of Consumption of Services]. Internal report. Environmental Systems Analysis, Chalmers University of Technology, Gothenburg, Sweden.

Brunklaus, B., 2008. Organising Matters for the Environment: Environmental Studies of Housing Management and Buildings. PhD thesis. Chalmers University of Technology, Göteborg, Sweden.

Brunswick, 2012. Bowling Center Products. Brunswick, Muskegon, MI.

Carter, C.R., Liane Easton, P., 2011. Sustainable supply chain management: Evolution and future directions. Int. J. Phys. Distribution Logist. Manag. 41(1), 46-62. https://doi.org/10.1108/09600031111101420.

Cementa, 2008a. Cementa AB Degerhamnsfabriken: Miljörapport för År 2007 [Cementa AB, Degerhamn Plant: Environmental Report for 2007]. Cementa. 
Cementa, 2008b. Miljörapport: För Cementa AB Skövdefabriken (1496-1102): År: 2007: Version: 1 [Environmental Report: For Cementa AB, Skövde Plant (1496-1102): Year 2007: Version 1]. Cementa, Skövde.

Cementa, 2008c. Miljörapport: För Cementa AB, Slitefabriken (0980-105): År: 2007: Version: 1 [Environmental Report: For Cementa AB, Slite Plant (0980-105): Year 2007: Version 1]. Cementa, Slite.

Cementa, n.d. Hållbarhetsredovisning 2007 [Sustainability Report 2007]. Cementa, Sockholm.

Curran, M.A. (Ed.), 2012. Life Cycle Assessment Handbook: A Guide for Environmentally Sustainable Products. Scrivener, Beverly, MA. https:// 10.1002/9781118528372.

Czarniawska, B., 2008. A Theory of Organizing. Edward Elgar, Cheltenham.

De Medeiros, J.F., Ribeiro, J.L.D., Cortimiglia, M.N., 2014. Success factors for environmentally sustainable product innovation: A systematic literature review. J. Clean. Prod. 65, 76-86. https://doi.org/10.1016/j.jclepro.2013.08.035.

Dieselnet, 2016. Emission standards: EU: Heavy-duty truck and bus engines. Dieselnet. https://www.dieselnet.com/standards/eu/hd.php (accessed 30 June 2017).

Faith-Ell, C., Balfors, B., Folkeson, L., 2006. The application of environmental requirements in Swedish road maintenance contracts. J. Clean. Prod. 14(2), 163-171. https://doi.org/10.1016/j.jclepro.2004.11.004.

Gemechu, E.D., Sonnemann, G., Remmen, A., Frydendal, J., Jensen, A.A., 2015. How to implement life cycle management in business? in: Sonnemann, G., Margni, M. (Eds.), Life Cycle Management. Springer, Dordrecht, pp. 35-50. https://doi.org/10.1007/978-94-0177221-1_4. 
Glaser, B.G., Strauss, A.L., 2006. The Discovery of Grounded Theory: Strategies for Qualitative Research. Aldine Transaction (a division of Transaction Publishers), New Brunswick, NJ.

Hatch, M.J., Cunliffe, A.L., 2006. Organization Theory: Modern, Symbolic, and Postmodern Perspectives, second ed. Oxford University Press, Oxford.

Hauschild, M.Z., Rosenbaum, R.K., Olsen, S.I. (Eds.), 2018. Life Cycle Assessment: Theory and Practice. Springer, Cham. https://doi.org/10.1007/978-3-319-56475-3.

Janssens-Maenhout, G., Crippa, M., Guizzardi, D., Muntean, M., Schaaf, E., Olivier, J.G.J., Peters, J.A.H.W., Schure, K.M., 2017. Fossil CO2 \& GHG Emissions of All World Countries. JRC Science for Policy Report. Publications Office of the European Union, Luxembourg. https://doi.org/10.2760/709792.

Jerksjö, M., Hallquist, Å., 2016. Measurements of Bus Emissions 2010-2015. Report number: B2254. IVL Swedish Environmental Research Institute, Stockholm.

Kallio, T.J., Nordberg, P., 2006. The evolution of organizations and natural environment discourse: Some critical remarks. Organ. Environ. 19(4), 439-457. https://doi.org/10.1177/1086026606294955.

Lindkvist, M., Baumann, H., 2017. Analyzing how governance of material efficiency affects the environmental performance of product flows: Comparison of product chain organization of swedish and dutch metal packaging flows. Recycl. 4(2), 23. https://doi.org/10.3390/recycling2040023.

Lindkvist, M., Baumann, H., 2015. The Influence of Organisational Practices on Environmental Performance: A Screening of the Organising of Nodes in Product Life Cycles in Six Test Cases. Report / Division of Environmental Systems Analysis, Chalmers University of Technology: 2015:14. Chalmers University of Technology, Gothenburg, Sweden. 
Lindkvist, M., Baumann, H., 2013. Bring on the 'soft' sciences: Grounding life cycle methods in three socio-material philosophies. 6th International Conference on Life Cycle Management, 25-28 August, Gothenburg, Sweden.

Lundberg, Ö. 2008. Management Matters - Linking Management of Buildings to Environmental Impacts in a Pilot Study of Supermarket Buildings. Report / Division of Environmental Systems Analysis, Chalmers University of Technology: 2008:3. Chalmers University of Technology, Göteborg, Sweden.

Maroušek, J., 2014. Significant breakthrough in biochar cost reduction. Clean Technol. Environ. Policy 16(8), 1821-1825. https://doi.org/10.1007/s10098-014-0730-y.

Maroušek, J., Kolář, L., Vochozka, M., Stehel, V, Maroušková, A., 2017. Novel method for cultivating beetroot reduces nitrate content. J. Clean. Prod. 168, 60-62. https://doi.org/10.1016/j.jclepro.2017.08.233.

Nilsson-Lindén, H., Baumann, H., Rosén, M., Diedrich, A., 2018. Organizing life cycle management in practice: Challenges of a multinational manufacturing corporation. Int. J. Life Cycle Assess. 23(7), 1368-1382. https://doi.org/10.1007/s11367-014-0818-y. SIK, 2009. Klimatpåverkan från Bröd - Kommunikationsunderlag. P80427. Utdrag ur Rapport till Brödinstitutet Januari 2009. [Climate Impact from Bread - Background Document for Stakeholder Communication. Excerpt from a Report to Brödinstitutet, from January 2009.] SIK.

Silverman, D., 2006. Interpreting Qualitative Data: Methods for Analysing Talk, Text and Interaction, third ed. SAGE, London.

Sivak, M., Schoettle, B., 2012. Eco-driving: Strategic, tactical, and operational decisions of the driver that influence vehicle fuel economy. Transp. Policy 22, 96-99. https://doi.org/10.1016/j.tranpol.2012.05.010. 
Sonnemann, G., Margni, M. (Eds.), 2015. Life Cycle Management. Springer, Dordrecht. https://doi.org/10.1007/978-94-017-7221-1.

Stripple, H., 2001. Life Cycle Assessment of Road: A Pilot Study for Inventory Analysis, second revised ed. IVL Swedish Environmental Research Institute, Gothenburg, Sweden.

Tengström, J., Izurieta, F., 2010. LCA of Stage Performances: Life Cycle Assessment of an Opera and a Theatre Stage Performance. Master's thesis. Chalmers University of Technology, Gothenburg.

Ukidwe, N.U., 2005. Thermodynamic Input-Output Analysis of Economic and Ecological Systems for Sustainable Engineering. PhD thesis. The Ohio State University.

Växjö Tingsrätt, 2007. Deldom: Mål Nr M 2739-05 [Sub Verdict: Case Number M 2739-05]. Miljödomstolen, Växjö Tingsrätt, Växjö.

Vold, M., Rønning, A., 1995. LCA of Cement and Concrete: Main Report. Stiftelsen Østfoldforskning, Fredrikstad.

Von Bahr, B., Hanssen, O.J., Vold, M., Pott, G., Stoltenberg-Hansson, E., Steen, B., 2003. Experiences of environmental performance evaluation in the cement industry: Data quality of environmental performance indicators as a limiting factor for benchmarking and rating. J. Clean. Prod. 11(7), 713-725. https://doi.org/10.1016/S0959-6526(02)00126-9.

Xie, G., 2016. Cooperative strategies for sustainability in a decentralized supply chain with competing suppliers. J. Clean. Prod. 113, 807-821. https://doi.org/10.1016/j.jclepro.2015.11.013. 


\section{Figure captions}

Fig. 1. The proposed approach combines two types of study. The figure is adapted from Lindkvist and Baumann (2013) with permission.

Fig. 2. Product flows and human actions typically considered in the proposed screening life cycle nodal organisation approach. A life cycle study of product flows and environmental impacts is combined with a study of an action net traced from a node of a product flow.

Fig. 3. Overview of the tested product life cycles. Italicised processes were not present in all subcases. Sources besides interviews and observation: for bowling, on leisure activities (Brunklaus, 2009b), bowling equipment (Brunswick, 2012), and theatre and opera (Tengström and Izurieta 2010); for bread, on production size (Andersson and Ohlsson, 1999) and bread types (SIK, 2009); for concrete Vold and Rønning (1995); and for road management Stripple (2001). 
Figure 1

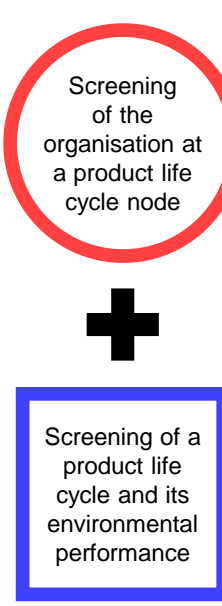

Screening life

cycle nodal

organisation

study

preening of a

environmental

performance 
Figure 2:

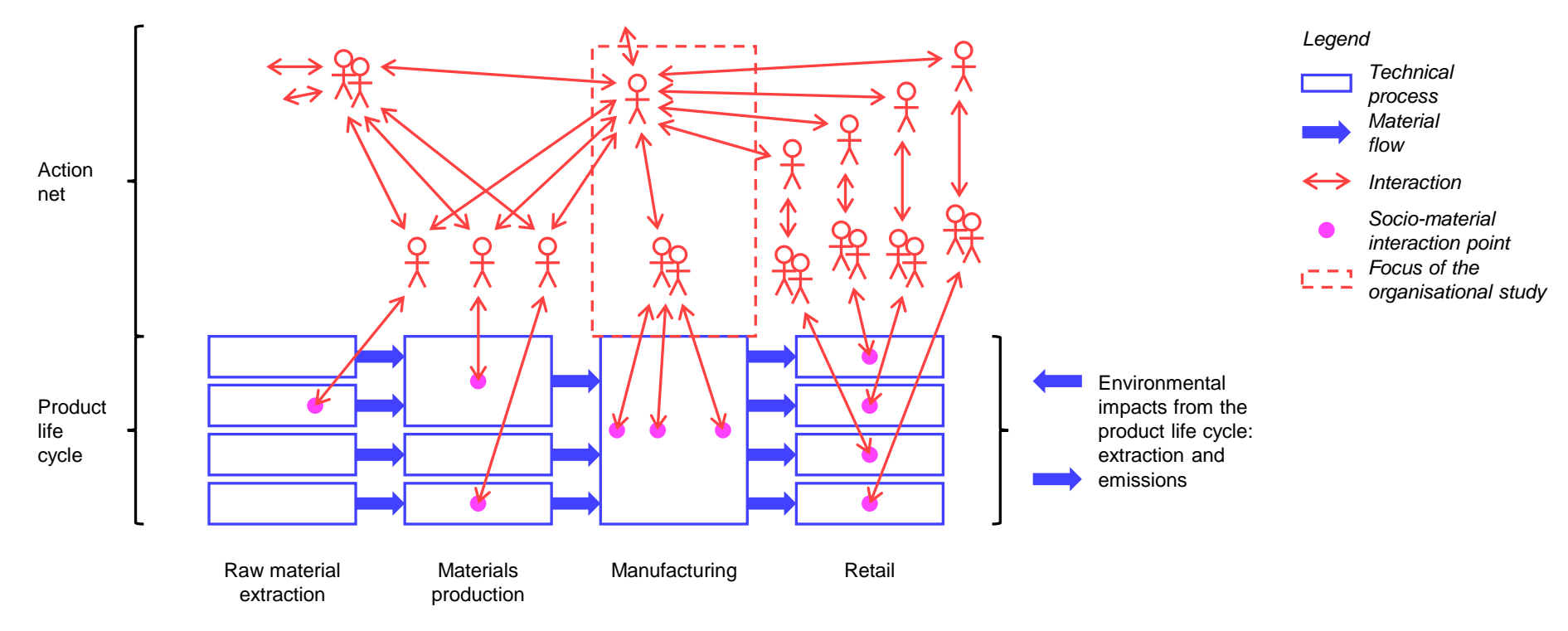




\section{Figure 3:}

Bowling:

\begin{tabular}{|c|c|c|c|c|}
\hline $\begin{array}{c}\text { Raw } \\
\text { materials } \\
\text { production }\end{array}$ & $\begin{array}{c}\text { Production } \\
\text { of supplies }\end{array}$ \\
\hline
\end{tabular}

Bread:

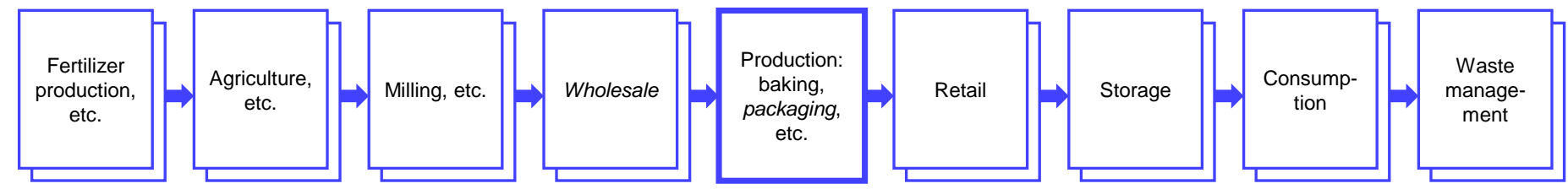

Coach services:

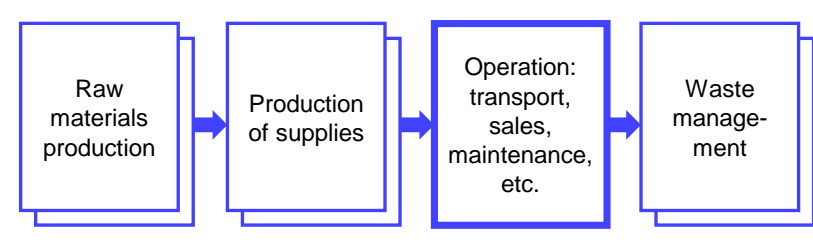

Concrete:

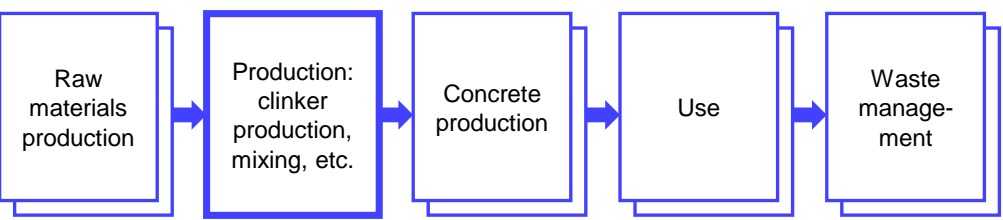

Road management:

\begin{tabular}{|c|c|c|c|}
\hline $\begin{array}{c}\text { Raw } \\
\text { materials } \\
\text { production }\end{array}$ & $\begin{array}{l}\text { Production } \\
\text { of supplies }\end{array}$ & $\begin{array}{l}\text { Operation: } \\
\text { road } \\
\text { lighting, } \\
\text { snow } \\
\text { clearing, } \\
\text { etc. }\end{array}$ & $\begin{array}{c}\text { Waste } \\
\text { manage- } \\
\text { ment }\end{array}$ \\
\hline
\end{tabular}

